\title{
BRAIN PEPTIDASE WITH A UNIQUE NEURONAL LOCALIZATION: THE HISTOCHEMICAL DISTRIBUTION OF DIPEPTIDYL-AMINOPEPTIDASE II $^{1}$
}

\author{
CHARLES GORENSTEIN, ${ }^{2}$ VINH T. TRAN, AND SOLOMON H. SNYDER ${ }^{3}$ \\ Departments of Neuroscience, Pharmacology and Experimental Therapeutics, Psychiatry, and Behavioral Sciences, The Johns Hopkins \\ University School of Medicine, Baltimore, Maryland 21205
}

\begin{abstract}
To assess whether specific peptidases regulate neuropeptide disposition, we have examined histochemically the localization of dipeptidyl-aminopeptidase II (DAP II). With $\beta$-naphthylamide $(\beta$-NA) substrates, this enzyme has a selectivity for lysyl-alanyl- $\beta$-NA. DAP II staining is highly localized to specific neuronal populations with no staining over glia. Areas in the brain with high densities of DAP II staining include the mitral cells in the olfactory bulb, polymorphic cells in the hippocampus, the paraventricular nucleus of the hypothalamus, and the anterior dorsal thalamus, Purkinje cells, and deep nuclei in the cerebellum. Staining occurs in virtually all cell groups in the inferior colliculus, red nucleus, oculomotor nucleus, and mesencephalic nucleus of the trigeminal nerve, the stratum album of the superior colliculus, as well as most cells in the cochlear and superior olivary nuclei. DAP II localizations do not correlate fully with those on any known neuropeptide. Of the numerous peptides evaluated, only glucagon competes substantially for the DAP II substrate, reducing enzymatic activity by $50 \%$ at a $2 \times 10^{-5}$ M concentration.
\end{abstract}

A large number of peptides have emerged as neurotransmitter candidates in the brain (Snyder, 1980). Most neurotransmitters are inactivated after synaptic release by neuronal re-uptake or enzymatic cleavage. Selective neuronal uptake systems for neuropeptides have not been demonstrated yet. While most neuropeptides can be degraded or cleaved from precursors by numerous peptidases, it is unclear whether any peptidase is associated selectively with a particular neuropeptide. Close anatomical juxtaposition of a particular peptidase with nerve terminals or receptors for a given neuropeptide would favor such an association. Peptidases might be localized histochemically by immunohistochemistry using antisera to the purified enzymes. Though two enkephalin-degrading enzymes, enkephalinase $A_{1}$ and $A_{2}$, have been solubilized from brain membranes and purified to homogeneity (Gorenstein and Snyder, 1980; C. Gorenstein and

\footnotetext{
${ }^{1}$ We thank Marla Bowman for technical assistance, Dawn C. Hanks for typing, and Drs. M. A. Zarbin and J. K. Wamsley for helpful discussions. This work was supported by United States Public Health Service Grants DA-00266 and NS-16374, Research Scientist Development Award DA-00074 to S. H. S., and a grant from the McKnight Foundation.

${ }^{2}$ Present address: Department of Pharmacology, University of California School of Medicine, Irvine, CA 62717.

${ }^{3}$ To whom correspondence should be addressed at Department of Neuroscience, The Johns Hopkins University School of Medicine, 725 North Wolfe Street, Baltimore, MD 21205.
}

S. H. Snyder, manuscript in preparation), it has not been possible to obtain selective antisera. Alternatively, histochemical stains can be based on the enzymatic activity of the enzyme protein. Aminopeptidases are assayed both biochemically and histochemically with artificial substrates comprising $\beta$-naphthylamide ( $\beta$-NA)- or 4 -methoxy- $\beta$-naphthylamide (MNA)-substituted amino acids (Gomori, 1954). Enzymatic hydrolysis of the peptide bond generates free $\beta$-NA or MNA which can be measured fluorometrically in biochemical studies or coupled to diazotized dyes which then precipitate for histochemical studies.

Aminopeptidases cleave single amino acids from the $\mathrm{NH}_{2}$ terminus of a peptide and can be readily assayed with $\beta$-NA or MNA substituted with a single amino acid. Dipeptidyl-aminopeptidases cleave dipeptides from the $\mathrm{NH}_{2}$ terminus of a peptide and also can be assayed with $\beta$-NA- or MNA-substituted dipeptides. Four distinct dipeptidyl-aminopeptidases (DAPs) which display selectivity toward particular naphthylamide substrates as well as specific $\mathrm{pH}$ optima have been described. DAP I (cathepsin C) cleaves glycyl-arginyl- $\beta-\mathrm{NA}$ at $\mathrm{pH} 6$. DAP II cleaves lysyl-alanyl- $\beta$-NA with a pH optimum of 5 . DAP III cleaves arginyl-arginyl- $\beta$-NA with a $\mathrm{pH}$ optimum of 8 to 9 , while DAP IV cleaves glycyl-prolyl- $\beta$-NA with a $\mathrm{pH}$ optimum of 8 (McDonald et al., 1968, 1971).

The histochemical method that we have employed is based on the enzymatic cleavage of lysyl-alanyl-MNA by 
DAP II. In the presence of the diazotized salt and fast blue $\mathrm{B}$, the liberated MNA precipitates as an insoluble azo.dye complex, demonstrating the site of enzyme activity. In the present study, we demonstrate a highly selective localization of DAP II activity to specific neuronal populations within the brain.

\section{Materials and Methods}

Histochemistry. Male Sprague-Dawley rats (150 gm) were perfused with $4 \%$ paraformaldehyde at a pressure of $100 \mathrm{~mm} \mathrm{Hg}$. Fifty-micrometer sagittal or coronal sections of rat brain were cut on a Vibratome. Sections were incubated in a solution of $0.1 \mathrm{M}$ sodium acetate containing $0.9 \% \mathrm{NaCl}, 1 \mathrm{mg} / \mathrm{ml}$ of lysyl-alanyl-4-methoxy- $\beta$-naphthylamide, and $1 \mathrm{mg} / \mathrm{ml}$ of fast blue $B$. Free floating sections were incubated at $37^{\circ} \mathrm{C}$ for $60 \mathrm{~min}$. After incubation, the sections were rinsed in $0.9 \%$ sodium chloride and treated with $2 \% \mathrm{CuSO}_{4}$ for 3 min. Following a $0.9 \%$ sodium chloride wash, the sections were mounted on glass slides and dehydrated through a series of graded alcohols and xylene. Then they were mounted in Permount (Fisher Scientific Co.). The red azo dye precipitate was stable for at least 3 months.

Localization of the various brain regions was accomplished with the aid of a brain atlas (Pellegrino et al., 1979). Acid phosphatase was localized as described by Barka and Anderson (1962).

Enzymatic assays. DAP II was partially purified from brain membranes. Membranes from rat brain were prepared and solubilized with Triton X-100 as described previously (Gorenstein and Snyder, 1980). The soluble extract was loaded onto a DEAE ( $O$-diethylaminoethyl)column equilibrated in $50 \mathrm{~mm}$ Tris (tris(hydroxymethyl)aminomethane), $\mathrm{pH} 7.7,0.1 \%$ Triton X-100. The column was developed with a linear gradient of sodium chloride. DAP II activity eluted between 0.25 and $0.3 \mathrm{M} \mathrm{NaCl}$.

The effect of various neuropeptides on DAP II activity was tested as follows. Reaction mixtures $(100 \mu \mathrm{l})$ contained $10 \mu \mathrm{l}$ of partially purified DAP II, $70 \mu \mathrm{l}$ of $0.2 \mathrm{M}$

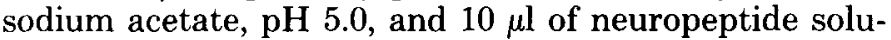
tion. The mix was incubated at $0^{\circ} \mathrm{C}$ for $5 \mathrm{~min}$ before adding $10 \mu \mathrm{l}$ of $0.01 \mathrm{~m}$ lysyl-alanyl- $\beta$-NA and then incubated at $37^{\circ} \mathrm{C} 15 \mathrm{~min}$. The reaction was terminated by boiling for $1 \mathrm{~min}$. Precipitated protein was removed by centrifugation and the $\mathrm{pH}$ was adjusted by additions of $0.9 \mathrm{ml}$ of $1 \mathrm{~m}$ Tris, $\mathrm{pH}$ 7.7. Fluorescence was measured at $355 \mathrm{~nm}$ excitation and $410 \mathrm{~nm}$ emission in an AmincoBowman spectrofluorometer.

\section{Results \\ Specificity of DAP II staining}

DAP II staining is highly localized to specific neuronal populations (Figs. 1 and 2) as well as to certain large blood vessels. We attempted to establish whether the observed staining represents DAP II activity or whether it might be related to the dye alone or to some generalized property associated with interactions of amino-acid-substituted $\beta$-naphthylamides and tissue.

To determine whether the staining reflects an enzymatic activity, we heated tissues. Brain slices cut at 50 $\mu \mathrm{m}$ in a Vibratome in the same way as those used for staining were heated in $0.1 \mathrm{M}$ sodium acetate buffer, $0.9 \%$ $\mathrm{NaCl}, \mathrm{pH} 5$, at $80^{\circ} \mathrm{C}$ for $5 \mathrm{~min}$. This treatment does not affect tissue integrity. Heated tissue slices then were stained for DAP II. Despite intact morphology, no DAP II staining was observed.

We evaluated staining with substrate alone in the absence of fast blue B or with fast blue B alone. In neither case was any DAP II type staining observed.

It is conceivable that the observed DAP II staining might represent the sequential removal of single amino acids from the substrate. In this case, the actual staining pattern would reflect the cleavage of alanine from MNA. Accordingly, we examined staining with alanyl-MNA, but at $\mathrm{pH} 5$, which is used for DAP II staining, no staining occurs in any of the brain regions examined. Interestingly, at $\mathrm{pH} 6.5$, staining with this substrate is associated almost exclusively with small blood vessels (C. Gorenstein and S. H. Snyder, manuscript in preparation).

To determine whether the DAP II staining might represent a nonspecific interaction that would occur with any dipeptide attached to MNA, we examined a series of dipeptide MNA substrates. At pH 5, no staining at all was observed with leucyl-alanyl-MNA, arginyl-arginylMNA, glycyl-prolyl-MNA, or glycyl-arginyl-MNA.

It would be desirable to determine whether DAP II staining is prevented by treating the slides with a specific inhibitor of this enzyme. We are not aware of any highly selective inhibitors of DAP II activity. However, puromycin is a partial inhibitor of DAP II activity. Unfortunately, in preliminary experiments, we found that puromycin itself reacts with the dye, causing a precipitate.

In summary, these lines of evidence indicate that the observed staining reflects DAP II enzymatic activity.

\section{Absence of association of DAP II staining with lysosomes}

In the pituitary gland, DAP II occurs in lysosomal particles (McDonald et al., 1968). Lysosomes are universal constituents of animal cells and are contained within glia as well as neurons. However, DAP II staining is observed exclusively within neurons with no evidence of staining in glia. Moreover, one would expect lysosomes to be distributed to a uniform extent among different neuronal populations, which does not fit with the localization of DAP II staining in particular neuronal groups.

As a further control, we stained for acid phosphatase, a well known lysosomally localized enzyme (not shown). Acid phosphatase staining is much more widespread than that of DAP II. Staining is observed in glia as well as in neurons and is contained ubiquitously within many neuronal populations.

Thus, it appears improbable that the DAP II activity observed in our histochemical studies is contained primarily within lysosomes.

\section{Regional localization of DAP II}

DAP II staining is confined to neurons with no staining observed in glia. Neuronal perikarya display the most striking stainirg with granular deposits concentrated throughout the cytoplasm but with no staining over the 
nucleus. In many instances, granular staining was observed in dendritic and axonal branches.

Telencephalon. Within the olfactory bulb, the mitral cell layer stains intensely (Fig. $1 A$ ). No staining is ob-
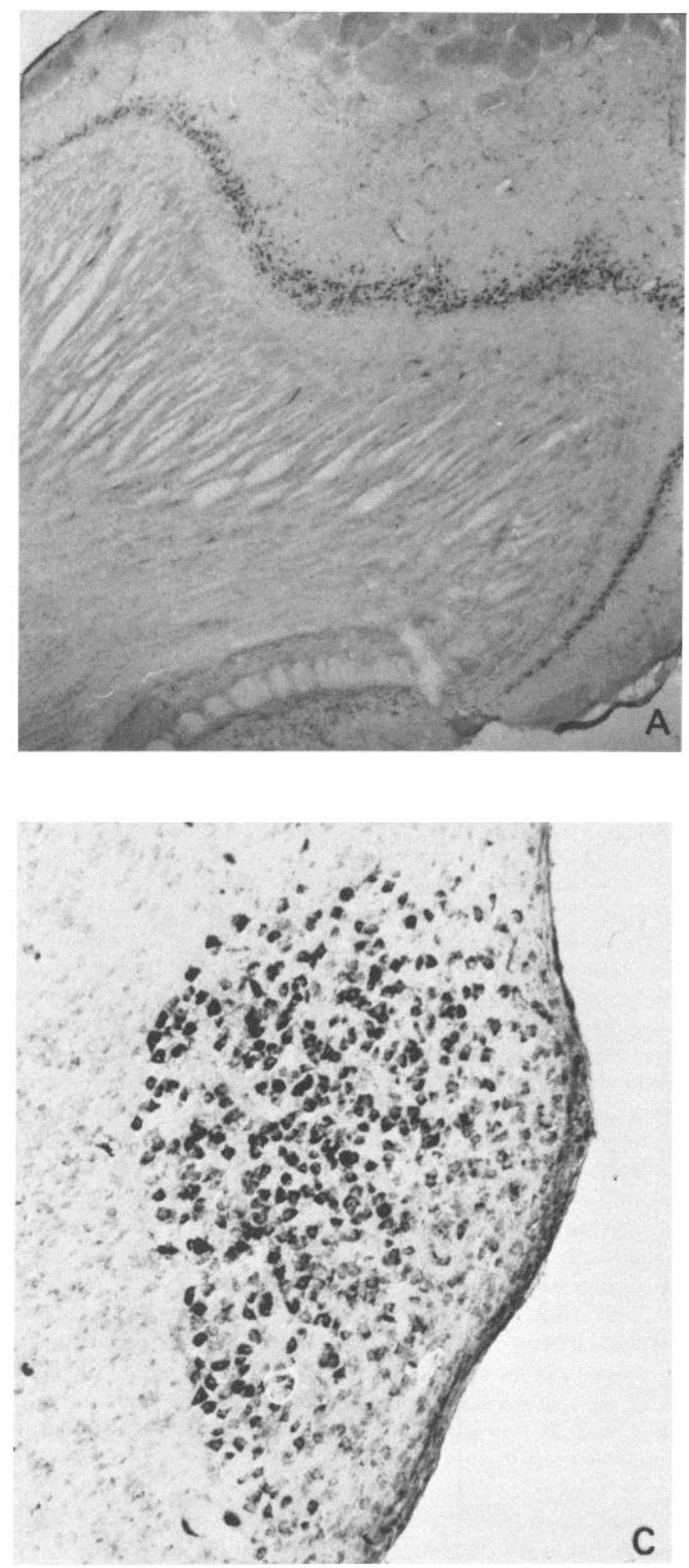

C served over the granular layer, while some diffuse staining is seen over glomeruli.

Staining in the hippocampus is confined to polymorphic cells within the dentate gyrus (Fig. 1B). Only
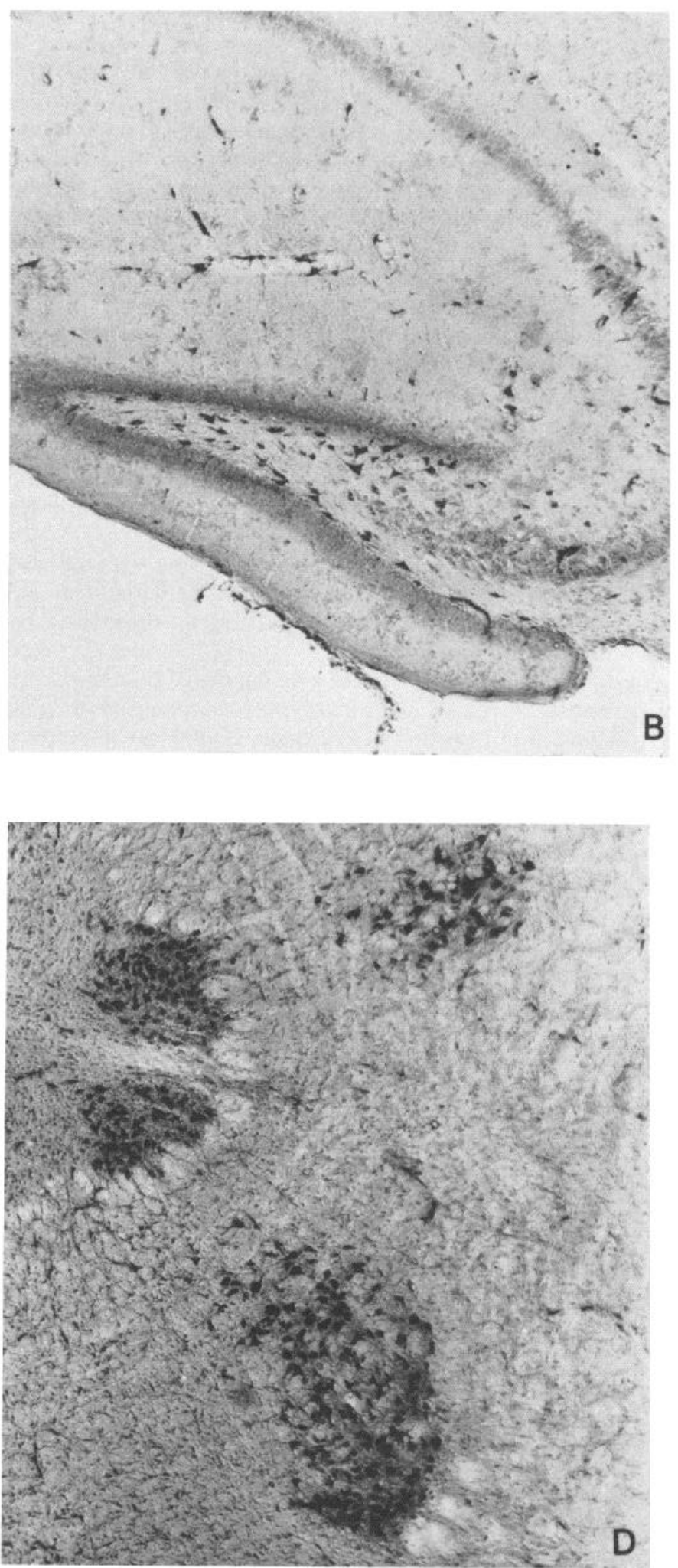

Figure 1. Localization of dipeptidyl-aminopeptidase II in brain slices. Sections were incubated with lysyl-alanyl-MNA and fast blue $\mathrm{B}$ as described under "Materials and Methods." $A$, Mitral cell layer in the olfactory bulb; magnification $\times 40$. B, Polymorphic cells in the dentate gyrus; magnification $\times 100$. C, Anterior dorsal nucleus of the thalamus; magnification $\times 150$. $D$, Red and oculomotor nuclei; magnification $\times 250$. 
slight diffuse staining occurs in the granular cells. No other areas of hippocampus are stained.

A limited amount of staining is seen in the cerebral cortex where it is confined to the parietal cortex in layers 3 and 5. Morphologically, the cells stained in these layers appear to be pyramidal cells.

A number of cells within the cortical amygdaloid nucleus are positive for DAP II. Intense staining occurs in the entorhinal cortex as well as in the polymorphic layer of the pyriform cortex. Cells in the globus pallidus stain, while very few cells stain in the caudate nucleus and putamen.

Diencephalon. In the hypothalamus, staining is confined to the paraventricular nucleus (Fig. 2C). Marginal staining is observed in cells of the supraoptic nucleus. No other nuclei of the hypothalamus are stained.

In the thalamus, staining is observed only in neuronal perikarya within the anterior dorsal nucleus (Fig. 1C). No staining occurs in any other nuclei of the thalamus.

Mesencephalon. Neuronal perikarya in the red nucleus and nucleus of the oculomotor nerve stain intensely (Fig. $1 D$ ). The selectivity of DAP II localization is evident in that staining includes neuronal elements throughout the extent of the red and oculomotor nuclei, while areas immediately adjacent are completely negative.

DAP II staining occurs throughout all levels of the inferior colliculus. By contrast, within the superior colliculus, DAP II staining is confined to neurons in the stratum album. In some sections of the superior colliculus, staining is well delineated, illustrating the discrete deposits of dye over the perikarya as well as associated axons and dendrites (Fig. $2 A$ ).

The mesencephalic nucleus of the trigeminal nerve possesses the most densely stained group of cells observed throughout the brain. Staining is observed throughout the rostrocaudal extent of this nucleus as well as in its most rostrorostral projections (Fig. $2 B$ ). Within this nucleus, staining occurs only in perikarya, while cellular processes are unstained.

Brain stem. Within the brain stem, staining is localized to several groups of cells. The cochlear, the vestibular, and superior olivary nuclei stain throughout all dimensions. No staining is seen in the pontine nucleus. Large motor neurons of the reticular formation of the pons and medulla are stained intensely. No staining is observed within the cervical spinal cord.

Cerebellum. Almost all Purkinje cells stain for DAP II (Fig. 2B). Similarly, all of the deep nuclei of the cerebellum are stained (Fig. 2D). Cells in the granular layer stain only slightly and in a diffuse nature, in contrast to the deep granular deposits apparent in the Purkinje cells and deep nuclei.

\section{Relationship of DAP II staining to neuropeptide localization}

The extremely discrete localization of DAP II staining suggests that it might be associated with the metabolism of some specific neuropeptide. We compared the localization of DAP II activity with the histochemically determined distribution of a variety of neuropeptides (Table I). None of the cell body localizations for known neuropeptides correspond fully to the cell groups enriched in DAP II. If DAP II were concerned with degradation of synaptically released peptides, one might expect IAP-IIcontaining cells to be innervated by terminals of the relevant peptidergic pathway. Though terminals for some neuropeptides are widely distributed, none correspond closely to the localization of DAP II.

Another approach to determining whether DAP II is associated physiologically with degradation of a specific neuropeptide would be to assess the affinity of various neuropeptides for DAP II activity. Accordingly, we solubilized DAP II activity from brain membranes and partially purified it by chromatography on DEAE-cellulose to separate it from other DAP activities.

The enzyme displays a $K_{m}$ for lysyl-alanyl-MNA of 0.1 mM. Lysyl-alanine inhibits activity with a $K_{i}$ of about 0.5 $\mathrm{mm}$, while arginyl-arginine is inactive at $1 \mathrm{~mm}$. The partially purified enzyme shows similar activity in cerebral cortex, hypothalamus, and cerebellum. We assayed the potencies of various neuropeptides in competing for the hydrolysis of lysyl-alanyl-MNA. Of all of the neuropeptides tested, only glucagon demonstrates substantial inhibitory potency, reducing DAP II activity by $50 \%$ at a $20 \mu \mathrm{M}$ concentration. In contrast, at a $100 \mu \mathrm{M}$ concentration, angiotensin I and II, Met- and Leu-enkephalin, substance $\mathrm{P}$, prolyl-leucyl-glycinamide, neurotensin, physalaemin, and eledoisin all failed to affect DAP II activity.

\section{Discussion}

The major finding of this study is that DAP II activity is highly localized to specific neuronal populations in various parts of rat brain. Similar localizations of DAP II activity occur in mouse brain. Unlike DAP II activity in the pituitary gland, the activity observed in brain appears not to be associated primarily with lysosomes. Substantial DAP II staining is seen in axons and dendrites, structures which contain very few lysosomes (Peters et al., 1976). However, we cannot rule out the possibility that certain lysosomal enzymes, including DAP II, occur only in specific neuronal cell groups and not in nonneuronal cells. It is unclear why brain DAP II functions at pH 5 which is optimal for lysosomal enzymes. Possibly, the $\mathrm{pH} 5$ activity is unique for actions of DAP II upon naphthylamide substrates, while with endogenous peptides, the $\mathrm{pH}$ optimum might be higher.

Substrate specificity of a peptidase can provide a major clue as to the enzyme's physiological substrate. The fact that lysyl-alanyl-MNA is the preferred naphthylamide substrate does not necessarily imply that the physiological substrate contains a lysyl-alanyl moiety. McDonald et al. (1968) found a marked difference between the substrate specificity of pituitary DAP II assayed with tripeptides as opposed to naphthylamide derivatives. Thus, pituitary DAP II is virtually inactive with alanylalanyl- $\beta$-naphthylamide, while alanyl-alanyl-alanine is the most active substrate evaluated in a series of 10 tripeptides.

In screening for peptides with affinity for DAP II, glucagon was the only potent peptide detected. The glucagon that we tested is the pancreatic type with a molecular weight of 3,000 . "Intestinal" type glucagon with a molecular weight of 8,000 to 12,000 has been demonstrated recently in the brain (Conlon et al., 1979; Loren et al., 1979; Tager et al., 1980). Samples of the 

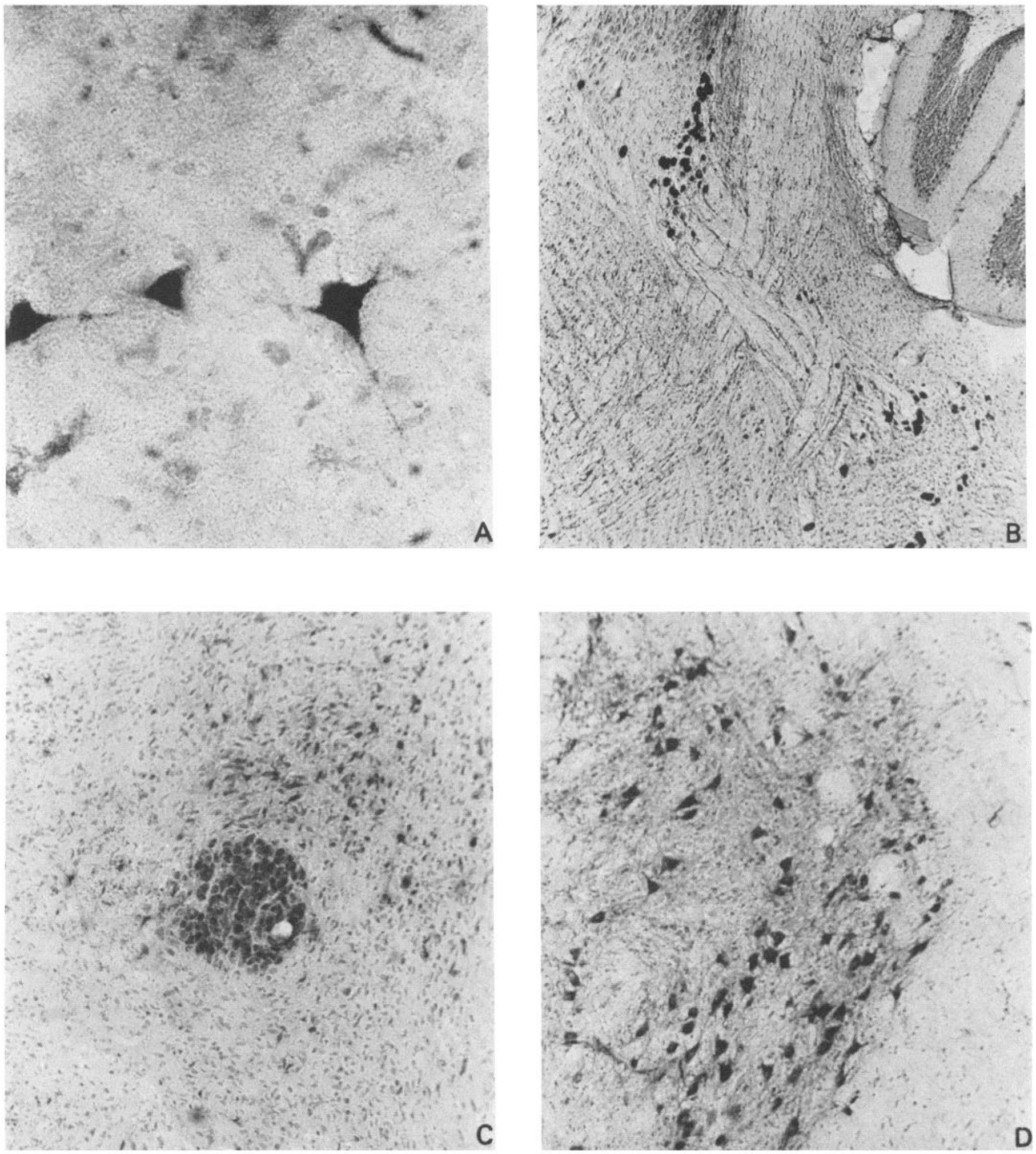

Figure 2. Localization of dipeptidyl-aminopeptidase II in brain slices. Sections were incubated with lysyl-alanyl-MNA and fast blue B as described under "Materials and Methods." $A$, Stratum album of the superior colliculus; magnification $\times 400$. B, Mesencephalic nucleus of the trigeminal nerve and cerebellar folia; magnification $\times 100$. $C$, Paraventricular nucleus of the hypothalamus; magnification $\times 150$. $D$, Deep cerebellar nucleus; magnification $\times 150$.

intestinal type glucagon were not available to us; therefore, it is unclear whether it is a substrate for DAP II. Since "intestinal" glucagon incorporates the amino acid sequence of pancreatic glucagon, it may be a biosynthetic precursor (Tager and Markese, 1979). Conceivably, low levels of rapidly turning over pancreatic type glucagon play a functional role in the brain and interact with DAP II. While intestinal glucagon has been detected through- 
TABLE I

Brain areas with demonstrable dipeptidyl-aminopeptidase II staining

Qualitative staining intensity was determined from the color of the precipitate. Areas which contained high levels of dipeptidyl-aminopeptidase II stained deep red, while areas with low enzymatic activity stained light red. Areas with high densities of cells or terminals for neuropeptides are indicated with the following abbreviations: $A G$, angiotensin; BR, bradykinin; CCK, cholecystokinin; ENK, enkephalin; Int. glucagon, intestinal glucagon; NT, neurotensin; SP, substance P; TRH, thyrotropin releasing hormone; VP, vasopressin. The numerical superscripts represent the following references: 1 , Kobayashi et al. (1978); 2, Emson et al. (1978); 3, Fuxe et al. (1976); 4, Elde et al. (1978); 5, Uhl et al. (1977); 6, Innis et al. (1979); 7, Correa et al. (1979); 8, Tager et al. (1980); 9, Loren et al. (1979).

\begin{tabular}{|c|c|c|}
\hline Region & $\begin{array}{l}\text { Intensity } \\
\text { of } \\
\text { Staining }\end{array}$ & $\begin{array}{l}\text { Neuropeptides } \\
\text { Present }\end{array}$ \\
\hline $\begin{array}{l}\text { Olfactory bulb: Mitral cell } \\
\text { layer }\end{array}$ & +++ & \\
\hline $\begin{array}{l}\text { Polymorphic cells of hippo- } \\
\text { campus }\end{array}$ & ++++ & \\
\hline Parietal cortex & + & \\
\hline Cortical amygdaloid nucleus & ++ & $\mathrm{NT}^{5}{ }^{5} \mathrm{SP}^{2}$ \\
\hline Entorhinal cortex & ++ & \\
\hline $\begin{array}{l}\text { Pyriform cortex: Polymorphic } \\
\text { layer }\end{array}$ & +++ & $\mathrm{CCK}^{6}$ \\
\hline Globus pallidus & ++ & ENK, ${ }^{\prime} \mathrm{SP}^{2}$ \\
\hline $\begin{array}{l}\text { Caudate nucleus and puta- } \\
\text { men }\end{array}$ & + & ENK $^{1}$ \\
\hline $\begin{array}{l}\text { Paraventricular nucleus of } \\
\text { hypothalamus }\end{array}$ & +++ & $\begin{array}{l}\mathrm{TRH},{ }^{4} \mathrm{BR},{ }^{7} \mathrm{ANG},{ }^{3} \\
\mathrm{VP},{ }^{4} \text { Int. gluca- } \\
\text { gon }^{8}\end{array}$ \\
\hline $\begin{array}{l}\text { Supraoptic nucleus of hypo- } \\
\text { thalamus }\end{array}$ & + & $V P^{4}$ \\
\hline $\begin{array}{l}\text { Antcrior dorsal nucleus of } \\
\text { thalamus }\end{array}$ & ++++ & Int. glucagon ${ }^{8,9}$ \\
\hline Red nucleus & ++++ & \\
\hline Oculomotor nucleus & ++++ & \\
\hline Inferior colliculus & ++++ & \\
\hline $\begin{array}{l}\text { Superior colliculus: Stratum } \\
\text { album }\end{array}$ & ++++ & \\
\hline $\begin{array}{l}\text { Mesencephalic nucleus of tri- } \\
\text { geminal nerve }\end{array}$ & +++++ & \\
\hline Cochlear nucleus & +++ & \\
\hline Vestibular nucleus & +++ & \\
\hline Superior olivary nucleus & +++ & \\
\hline Pontine reticular formation & +++ & \\
\hline Medullary reticular formation & +++ & \\
\hline Purkinje cells of cerebellum & ++ & \\
\hline Deep cerebellar nuclei & ++++ & \\
\hline
\end{tabular}

out the brain by radioimmunoassay, histochemical studies reveal substantial numbers of immunoreactive glucagon cells primarily in the paraventricular nucleus of the hypothalamus (Tager et al., 1980). Immunoreactive fibers are most highly concentrated in the paraventricular nuclei of the hypothalamus and in the dorsal thalamus (Loren et al., 1979). Interestingly, the paraventricular nucleus of the hypothalamus and anterior dorsal nucleus of the thalamus are among the most DAP-II-enriched brain areas.

Chromogenic substrates, such as $\beta$-naphthylamide peptide derivatives, may provide a valuable tool for the study of peptidases associated with neuropeptides. Biochemical assays for peptidases utilizing the natural neu- ropeptides are often tedious, requiring chromatographic separation of fragments formed by enzymatic hydrolysis. By contrast, biochemical assays of peptidases with $\beta$ naphthylamide substrates can be conducted by simple fluorometric analysis and used for both biochemical and histochemical studies.

Because the substrate specificity of peptidases determined with $\beta$-naphthylamide may differ greatly from the substrate specificity of the same enzyme for a natural peptide, we do not know whether DAP II is, in fact, only a dipeptidyl-aminopeptidase when it acts on its physiological substrate. Thus, it is unclear as well whether DAP II serves to inactivate a biologically occurring peptide or is involved in the biosynthesis of a peptide by cleavage from a larger precursor.

\section{References}

Barka, T., and P. J. Anderson (1962) Histochemical methods for acid phosphatase using hexazonium pararosaniline as coupler. J. Histochem. Cytochem. 10: 741-753.

Conlon, J. M., W. K. Samson, K. E. Dobbs, L. Orci, and R. H. Unger (1979) Glucagon-like polypeptides in canine brain. Diabetes 28: 700-702.

Correa, F. M. A., R. B. Innis, G. R. Uhl, and S. H. Snyder (1979) Bradykinin-like immunoreactive neuronal systems localized histochemically in rat brain. Proc. Natl. Acad. Sci. U. S. A. 76: $1489-1493$.

Elde, R., T. Hokfelt, O. Johansson, A. Ljungdahl, G. Nilsson, and S. L. Jeffcoate (1978) Immunohistochemical localization of peptides in the nervous system. In Centrally Acting Peptides, J. Hughes, ed., pp. 17-36, Macmillan, London.

Emson, P. C., T. M. Jessell, G. Paxinos, and A. C. Cuello (1978) Substance $\mathbf{P}$ in the amygdaloid complex, red nucleus and stria terminalis of the rat brain. Brain Res. 149: 97-105.

Fuxe, K., D. Ganten, T. Hokfelt, and P. Bolme (1976) Immunohistochemical evidence for the existence of angiotensin IIcontaining nerve terminals in the brain and spinal cord in the rat. Neurosci. Lett. 2: 229-234.

Gomori, G. (1954) Chromogenic substrates for aminopeptidase. Proc. Soc. Exp. Biol. Med. 87: 559-561.

Gorenstein, C., and S. H. Snyder (1980) Enkephalinases. Proc. R. Soc. Lond. (Biol.) 210: 123-132.

Innis, R. B., F. M. A. Correa, G. R. Uhl, B. Schneider, and S. H. Snyder (1979) Cholecystokinin octapeptide-like immunoreactivity: Histochemical localization in rat brain. Proc. Natl. Acad. Sci. U. S. A. 76: 521-525.

Kobayashi, R., M. Palkovitz, R. J. Miller, K. J. Chang, and P. Cuatrecasas (1978) Hypophysectomy does not alter rat brain enkephalin distribution. Life Sci. 22: 527-530.

Loren, I., J. Alumets, R. Hakanson, F. Sundler, and J. Thorell (1979) Gut-type glucagon immunoreactivity in nerves of the rat brain. Histochemistry $61: 335-341$.

McDonald, J. K., T. J. Reilly, B. B. Zeitman, and S. Ellis (1968) Dipeptidyl arylamidase II of the pituitary. Properties of lysylalanyl- $\beta$-naphthylamide hydrolysis: Inhibition by cations, distributions in tissues and subcellular localization. $J$. Biol. Chem. 243: 2028-2037.

McDonald, J. K., P. X. Callahan, and S. Ellis (1971) Polypeptide degradation by dipeptidyl aminopeptidase I (cathepsin C) and related peptidases. In Tissue Proteinases, A. J. Barrett and J. T. Dingle, eds., pp. 69-107, North Holland, Amsterdam.

Pellegrino, L. J., A. S. Pellegrino, and A. J. Cushman (1979) $A$ Stereolaxic Allas of the Rat Brain, Plenum Press, New York. Peters, A., S. L. Palay, and H. Webster (1976) The Fine Structure of the Nervous System: The Neurons and Supporting 
Cells, W. B. Saunders Co., Philadelphia.

Snyder, S. H. (1980) Brain peptides as neurotransmitters. Science 209: 976-983.

Tager, H. S., and J. Markese (1979) Intestinal and pancreatic glucagon-like peptides. J. Biol. Chem. 254: 2229-2233.

Tager, H., M. Hohenboken, J. Markese, and R. J. Dinerstein
(1980) Identification and localization of glucagon-related peptides in rat brain. Proc. Natl. Acad. Sci. U. S. A. 77: 62296233.

Uhl, G. R., M. J. Kuhar, and S. H. Snyder (1977) Neurotensin: Immunohistochemical localization in rat central nervous system. Proc. Natl. Acad. Sci. U. S. A. 74: 4059-4063. 